\title{
PENDEKATAN METODE TRIGONOMETRI PADA APLIKASI PEMANTAUAN PROGRES PEMBANGUNAN JALAN BERBASIS ANDROID
}

\author{
Dixy Abdul Rochman $\mathbf{S}^{1}$, Lisa Kristiana ${ }^{2}$, Marisa Premitasari ${ }^{3}$ \\ Program Studi Informatika, Fakultas Teknologi Industri \\ Institut Teknologi Nasional \\ Jl. PKH. Mustopha No.23, Neglasari, Cibeunying Kaler, Kota Bandung \\ $\underline{\text { adrianodicky26@gmail.com }{ }^{1}} \underline{\text { lisa@itenas.ac.id }{ }^{2}} \underline{\text { marisa.premitasari@gmail.com }}$
}

\begin{abstract}
Abstrak
Industri konstruksi seperti pembangunan jalan tentunya akan memiliki banyak risiko dan ketidak pastian dalam proses pelaksanaannya bila dibandingkan dengan industri lainnya. Selain terkendala masalah waktu, biaya dan mutu pekerjaan juga menjadi kendala pada setiap pelaksanaan proyek di bidang jasa konstruksi Penelitian ini dimulai dengan pengumpulan data keadaan dan perencaan di lapangan yang di input oleh petugas pemerintahan. Semua titik pembangunan di simpan dalam database. menggunakan aplikasi android untuk monitoring, petugas yang melakukan pengawasan diperlukan untuk berada di titik yang telah di tentukan untuk dapat memperbaharui status pembangunan jalan pada titik tersebut. Pada pengambilan gambar, proses trigonometri akan langsung menampilkan outline jalan lurus, berbelok $90^{\circ}$ dan berkelok untuk arahan foto pengambilan gambar. Akan tetapi Pada aplikasi progres pemantauan jalan yang panjang akan membutuhkan waktu yang sedikit lama dalam pengambilan titiknya perlu menunggu kurang lebih 30 detik supaya GPS bisa membaca koordinat dengan benar.
\end{abstract}

Kata kunci:

Trigonometri, Monitoring, GPS

\begin{abstract}
The construction industry such as road construction deals with many problems and uncertainty in the implementation process. In addition, time, cost and quality of work issues are also the focus of project implementation in the field of research
\end{abstract}

services, It starts with the data planning and location coordinates which are aggregated from the project's site by the officer. Those data planning and location coordinates are pin pointed and stored in databases. each point consists of Longitude, Latitude, Road type, and road width. Using the Android application for monitoring, the officer conducts the supervision as required for the determined point in order to update the road construction status, the trigonometric process will directly display the right and left lines for the direction of the photo capturing. however, a long road capturing, the system will take approximately 30 seconds so that GPS can read coordinates correctly

Keywords:

Trigonometry, Monitoring, GPS.

\section{Pendahuluan}

Industri konstruksi seperti pembangunan jalan tentunya akan memiliki banyak risiko dan ketidak pastian dalam proses pelaksanaannya bila dibandingkan dengan industri lainnya. Hal ini disebabkan proses pelaksanaan dari proyek konstruksi tersebut yang membutuhkan waktu cukup lama serta melibatkan banyak pihak dalam menyelesaikan suatu masalah. Selain terkendala masalah waktu, biaya dan mutu pekerjaan juga menjadi kendala pada setiap pelaksanaan proyek di bidang jasa konstruksi. Ketiga kendala tersebut diatas yaitu waktu, biaya dan mutu selanjutnya menjadi sasaran bagi setiap pelaksanaan proyek yang didefinisikan sebagai tepat waktu, tepat biaya dan tepat mutu. Suatu proyek yang dilaksanakan oleh suatu perusahaan jasa konstruksi dapat dikatakan berhasil jika ketiga sasaran tersebut diatas terpenuhi

Dixy Abdul Rochman S, Lisa Kristiana, Marisa Premitasari 
[1]. Berdasarkan hal tersebut diperlukan adanya suatu sistem pemantauan progres pembangunan jalan agar pelaksanaan pembangunan dapat efisien dalam segi waktu, biaya dan mutu.

Keterlambatan waktu proyek merupakan suatu peristiwa yang selalu terjadi pada setiap proyek. Keterlambatan pada proyek akan berakibat pada kemunduran waktu dimana akan mengurangi keutungan yang telah ditargetkan oleh kontraktor yang menangani proyek tersebut. Keterlambatan waktu juga dapat disebabkan oleh buruknya manajemen proyek yang diterapkan dan juga kesalahan-kesalahan sumber daya manusia di dalamnya [2].

Berdasarkan permasalahan diatas dibangunlah sebuah aplikasi yang berfungsi untuk memantau dan melaporkan setiap pekerjaan jalan yang menggunakan fungsi pendekatan trigonometri untuk menentukan titik jarak yang di tangkap oleh kamera dengan jarak sebenarnya yang sedang dikerjakan dengan mengukur panjang jalan, lebar jalan agar aplikasi dapat mengikuti jalan yang sedikit berkelok, dan akan langsung terkontrol oleh penanggungjawab yang berada di luar lapangan atau pusat. Untuk lebar jalan akan secara otomatis diukur menggunakan koordinat pada GPS yang nanti akan secara otomatis menyesuaikan dengan lebar jalan ada di lapangan, GPS Lock yang berfungsi untuk mengunci lokasi yang telah ditentukan sehingga tidak bisa mengambil gambar apabila penanggungjawab di lapangan tidak berada di tempat yang telah ditentukan

Di dalam suatu proyek dibutuhkan sebuah sistem pengendalian proyek yang nantinya diharapkan dalam pelaksanaan proyek tersebut senantiasa berada pada arah tujuan yang hendak dicapai. Pengendalian pelaksanaan proyek adalah awal monitoring. Agar monitoring berjalan maksimal [2]. Dari uraian diatas maka penelitian ini memiliki rumusan masalah sebagai berikut :

1. Penentuan titik pembangunan proyek menggunakan GPS lock.

2. Perhitungan panjang jalan yang dilakukan pembangunan menggunakan metode trigonometri.

3. Akurasi perhitungan Panjang jalan menggunakan metode trigonometri.

Penelitian ini bertujuan untuk menerapkan pendekatan metode trigonometri untuk pengukuran jalan pada smartphone saat di lapangan dan memastikan pelaporan progres pembangunan agar berada tepat di titik koordinat yang telah di tentukan dan perbandingan pengukuran panjang dan lebar jalan antara aplikasi dan sebenarnya yang didukung fungsi GPS lock untuk memastikan penanggung jawab di lapangan berada pada lokasi yang telah di tentukan oleh penanggung jawab pusat.

Adapun ruang lingkup dari penelitian ini adalah sebagai berikut:

1. Ada beberapa batasan masalah saat perancangan sistem agar pembahasan tidak meluas. Berikut adalah batasan masalah.

2. Pembuatan aplikasi menggunakan Android Studio versi 3.3.

3. Sistem hanya bisa memantau pekerjaan pada konstruksi jalan yang lurus dan berbelok 90

4. $\circ$.

5. Sistem yang digunakan hanya menerima data dari smartphone pengawas dilapangan yang telah terinstall aplikasi yang telah dibuat .

6. Validasi account berdasarkan id yang telah di daftarkan terlebih dahulu oleh pihak pimpinan.

7. Jumlah user dibatsi sesuai dengan perencanaan saat rapat kerja.

8. Pengambilan gambar menggunakan Samsung s6 edge.

\section{KAJIAN LITERATUR}

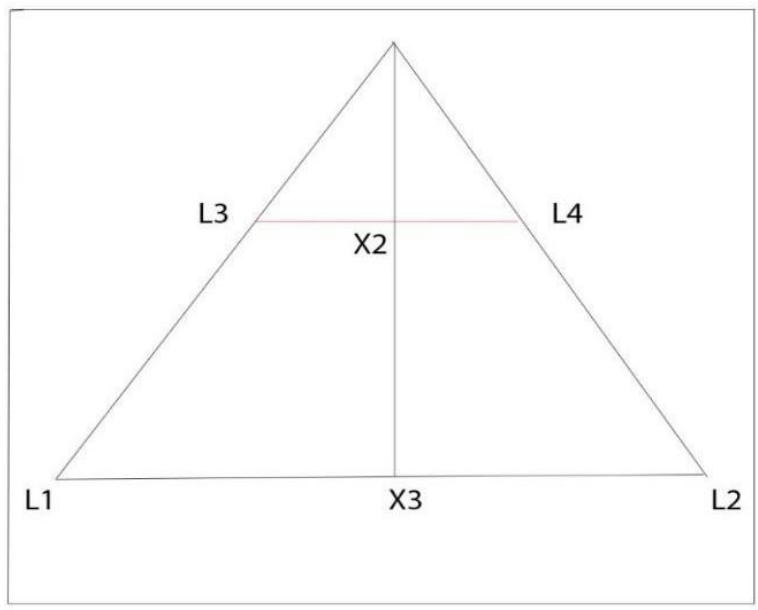

Gambar 1 Layout Segitiga

Trigonometri adalah salah satu cabang ilmu matematika yang merupakan ilmu mengenai hubungan relasi antara sudut dan sisi - sisi pada suatu segitiga. Dalam mempelajari segitiga pada trigonometri, Seperti yang terlihat pada Gambar 1, maka segitiga itu harus mempunyai tepat satu sudutnya $90^{\circ}$ artinya segitiga itu

Dixy Abdul Rochman S, Lisa Kristiana, Marisa Premitasari 
tidak lain adalah segitiga siku-siku. Trigonometri sering digunakan dalam perhitungan, di antaranya seperti ilmu perbintangan (Astronomi), teknik sipil, dan konstruksi.Pada Gambar 2 menjelaskan tentang layout grid bagaimana cara penggunaan dan perhitungan segitiga pada Gambar 1.

L1 adalah lebar kiri dan L2 adalah lebar kanan, Untuk X3 sampai dengan X2 menggunakan rumus lensa cembung, focal length kamera masuk ke perhitungan dengan pixel per inch dan pada kamera akan didapatkan nilai X2 sampai dengan X3, setelah itu akan dicari X2 sampai titik ujung segitiga panjangnya berapa menggunakan rumus perbandingan.

$$
\frac{L 1+L 2}{X 3+X 2}=\frac{L 3+L 4}{X 2+Z}
$$

Dalam rumus diatas diambil dari ujung segitiga, setelah itu akan digambar pada aplikasi. Karena lensa pada smartphone terhitung lensa cembung, oleh karena itu digunakanlah rumus lensa cembung. selanjutnya mencari bagaimana agar mencocokkan untuk pendekatan menjadi rumus panjang X2-X3.

Rumus lebar atas : lebar bawah /Panjang bawah = lebar atas / Panjang atas, Panjang atas di dapat dari titik $\mathrm{X} 2$ ke titik tengah layar. Titik tengah layers sama dengan samping sama dengan lebar layers smartphone dibagi 2. Atas layar sama dengan tinggi layar smartphone dibagi 2. Aplikasi mengambil X2 dan menggambarkan dari titik tersebut ke kanan dan ke kiri. Setelah itu maka akan didapat L3 dan L4.

\section{ANALiSis DAN PERANCANGan}

\section{Alur Sistem Aplikasi}

Penjelasan langkah - langkah alur kerja sistem adalah sebagai berikut:

1. GPS Lock memeriksa koordinat yang telah di tentukan oleh pimpinan proyek yang nanti akan di terima oleh mandor proyek.

2. Jika lokasi sudah cocok maka di tahap ini menggunakan algoritma pengulangan atau iterasi berfungsi untuk menghitung panjang awal $1 \mathrm{x}$ panjang akhir $1 \mathrm{x}$ lebar awal $1 \mathrm{x}$ dan lebar akhir $1 \mathrm{x}$ jika lebih dari 4 maka akan lanjut pada proses GPS lock.

3. Jika sesuai kamera akan terbuka, jika tidak kamera tidak akan bisa terbuka dan akan memberika peringatan.
4. Jika tidak sesuai akan masuk kembali ke menu GPS lock.

5. Apabila jarak dan koordinat telah di ketahui, maka deskripsi pelaporan progress dan koordinat akan di laporakan kepada pimpinan proyek yang bertanggung jawab penuh atas proyek pembangun jalan tersebut.

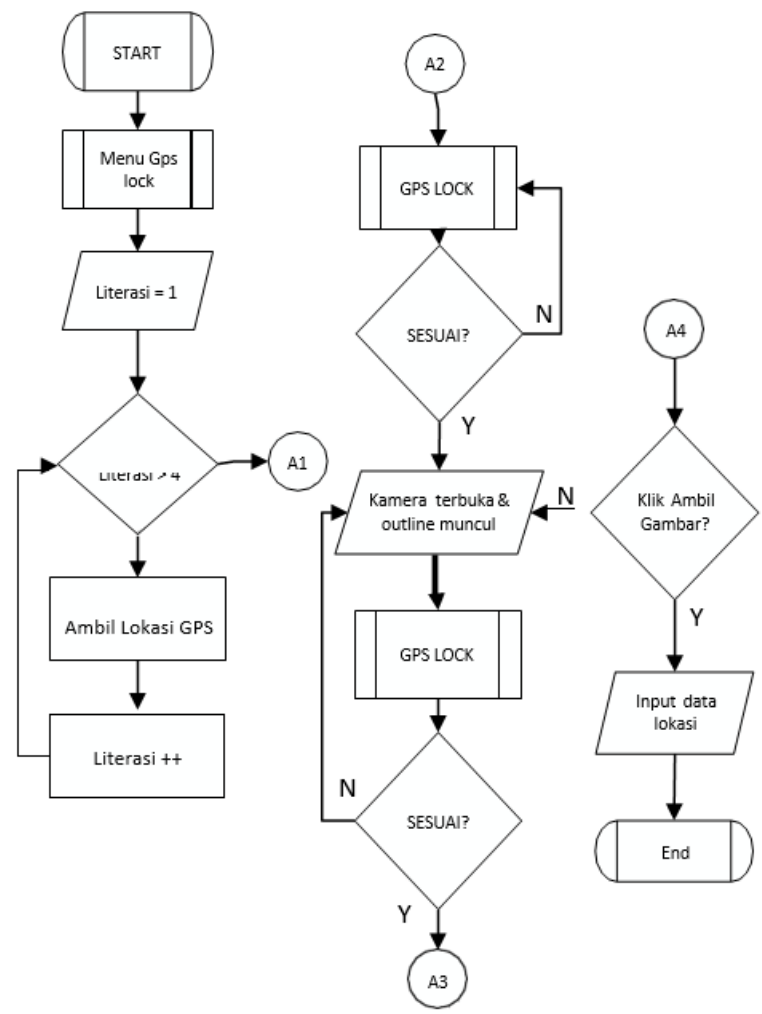

Gambar 2 Alur kerja system pada aplikasi

Blok Diagram Monitoring Progress Pembangunan Jalan

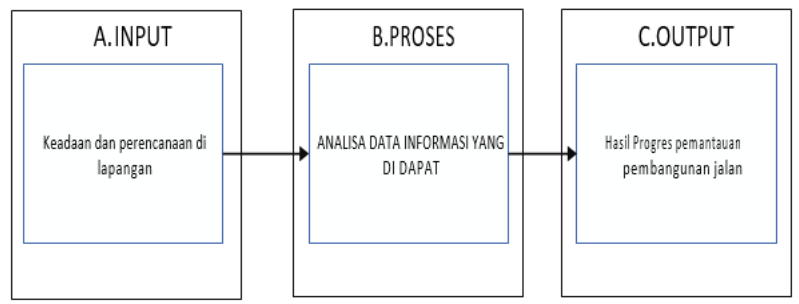

Gambar 3 Blok Diagram Proses

A. Input

1. Data titik pembangunan jalan (Longtitude, Latitude, Jenis Jalan, Deskripsi).

2. Data pengukuran kordinat data GPS panjang

Dixy Abdul Rochman S, Lisa Kristiana, Marisa Premitasari 
jalan dan lebar jalan.

\section{B. Proses}

1. Sistem pemantauan progres pada android akan mengirimkan laporan progres pembangunan jalan ke database.

2. Aplikasi Server (monitoring) akan melakukan request query secara POST.

3. Cloud Database akan mengirimkan data pemantauan progres yang telah di kirimkan melalui aplikasi client (Surveyor) terhadap Aplikasi Server (Monitoring).

4. Dengan demikian data pemantauan progres telah tersimpan di Database Server.

5. Pengguna aplikasi berada pada titik pembangunan, pengguna mengambil gambar jalanan dengan mencocokan jalan dengan outline, pengguna memasukan data mengenai pembangunan.

6. Dengan telah tersedianya data pemantauan progres di server database maka sistem pemantauan progres yang ada di smartphone pengawas yang berada di luar lapangan pengerjaan proyek dapat mengaksesnya.

\section{Output}

Output berupa hasil progres pemantauan pembangunan jalan di lapangan dan hasilnya akan di tampilkan pada smartphone pemantau.

\section{Hasil Pengujian}

Pengujian yang dilakukan pada sistem yaitu data akan di bandingkan dengan kedua grafik yaitu data panjang asli yang dihitung dengan menggunakan meteran ukur dengan maximal ukuran pada meteran yaitu 100 meter dan yang kedua di ukur menggunakan GPS dengan cara mengukur 2 buah jarak koordinat awal dan akhir.

Panjang jalan dengan kontur jalan lurus panjang sebenarnya adalah 25 meter panjang jalan maksimum telah ditentukan oleh pihak owner dan lebar sebenarnya 4,65 meter.

berikut cara pengukurannya pertama GPS akan membaca titik kordinat yang telah ditentukan sebelumnya jika sesuai maka kamera akan terbuka dan untuk mengukur panjang dan lebar jalan digunakan kordinat GPS untuk mengukurnya dengan cara berjalan dari titik awal sampai dengan titik tujuan dengan menekan tombol pada layar smartphone menekan sekali untuk titik awal dan menekan selanjutnya untuk titik akhir dan selanjutnya untuk mengukur lebar jalan melakukan hal yang sama namun pada pengukuran lebar jalan dimulai dari sisi kanan jalan hingga kiri jalan, setelah itu akan muncul panjang dal lebar jalan dan akan membentuk segitiga seperti Gambar 4 layout jalan lurus untuk membantu layout pengambilan gambar monitoring progres pembangunan jalan, pengambilan lokasi berada di Jl. Cikutra Baru Raya 25-28, Neglasari, Kec. Cibeunying Kaler, Kota Bandung, Jawa Barat 40124.

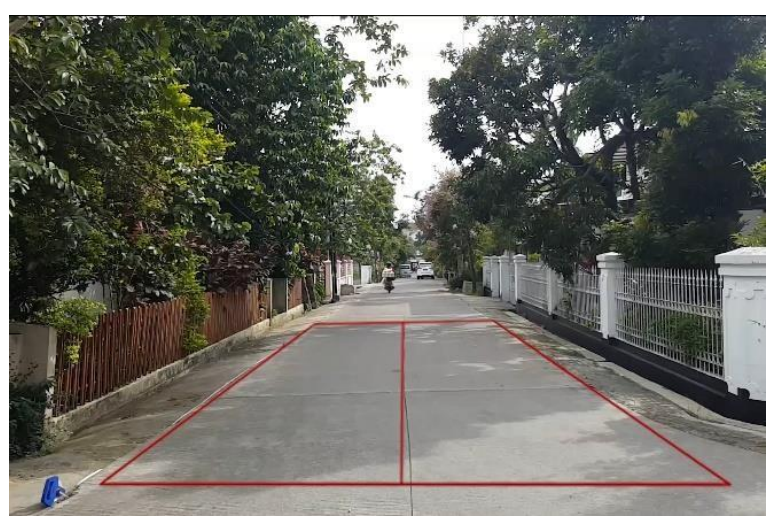

Gambar 4 Layout jalan lurus

Berikut grafik yang di dapat.

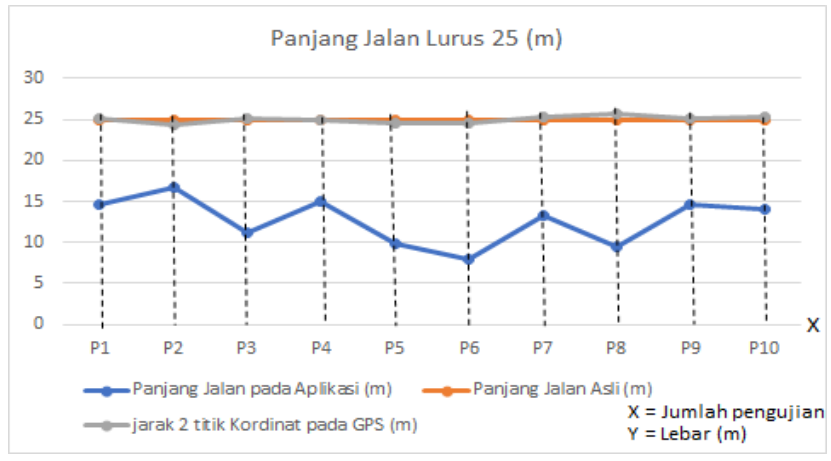

Gambar 5 Panjang jalan lurus

Dixy Abdul Rochman S, Lisa Kristiana, Marisa Premitasari

Jurnal Ilmiah Teknologi Informasi Terapan Volume 6, No 2, 15 April 2020 


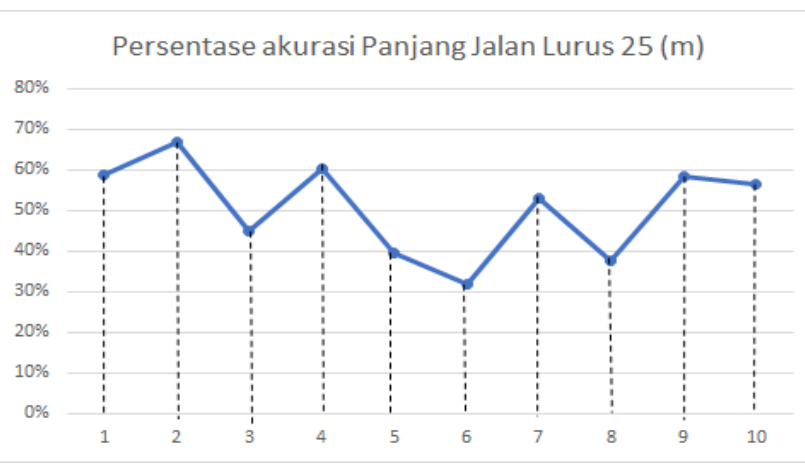

Gambar 6 Presentase akurasi Panjang jalanlurus 25 meter

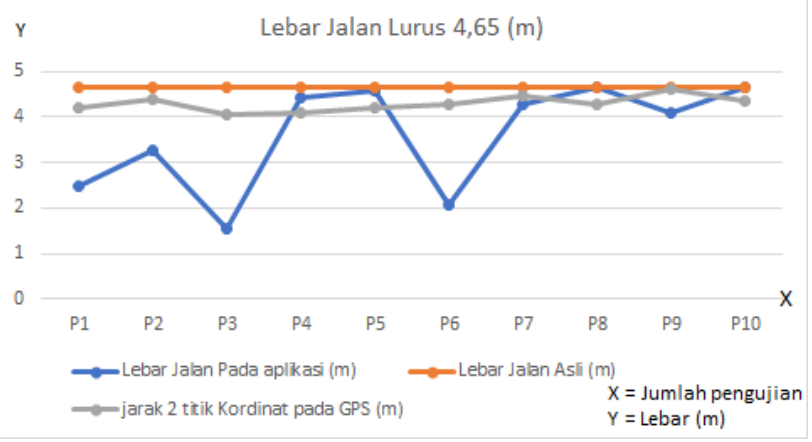

Gambar 7 Lebar jalan lurus

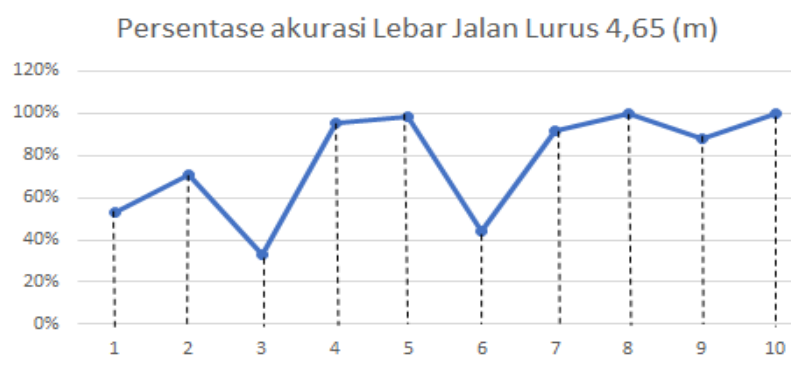

Gambar 8 Presentase akurasi lebar jalan lurus 4.65 meter

Statistik data jalan lurus pada gambar 6 Lebar jalan lurus di dapatkan yang pertama panjang jalan dengan statistik sangat jauh dari data sebenarnya, sumbu $\mathrm{Y}$ menunjukan lebar jalan atau panjang jalan dengan satuan meter dan sumbu $X$ adalah jumlah pengujiannya.

Statistik data lebar jalan dengan pola meningkat presisi mendekati nilai data jalan sebenarnya. Faktor yang mempengaruhi adalah karena lebar jalan yang tidak terlalu lebar atau pendek sehingga GPS gampang untuk menangkap koordinat dengan presisi dan pergerakan operator pada saat pengambilan titik kanan jalan dan kiri yang tidak terlalu cepat.

Pengujian selanjutnya adalah mengukur panjang dan lebar jalan yang berkelok dengan panjang sebenarnya 10 meter dan lebar sebenarnya 5,25 meter berikut grafik yang didapat dari pengujian diambil 5 sampel pertiap pengujian.

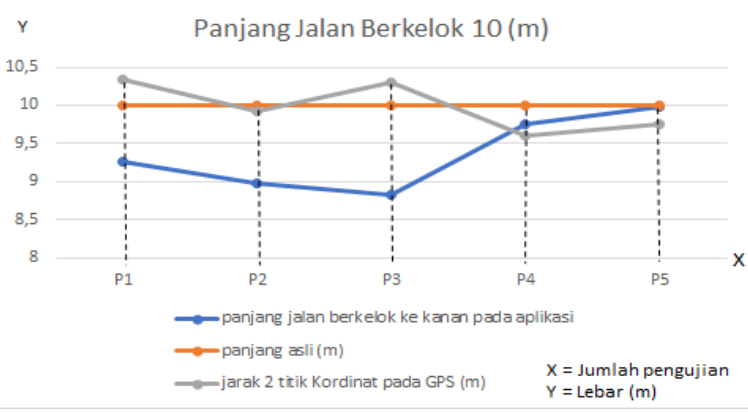

Gambar 9 Panjang jalan berbelok

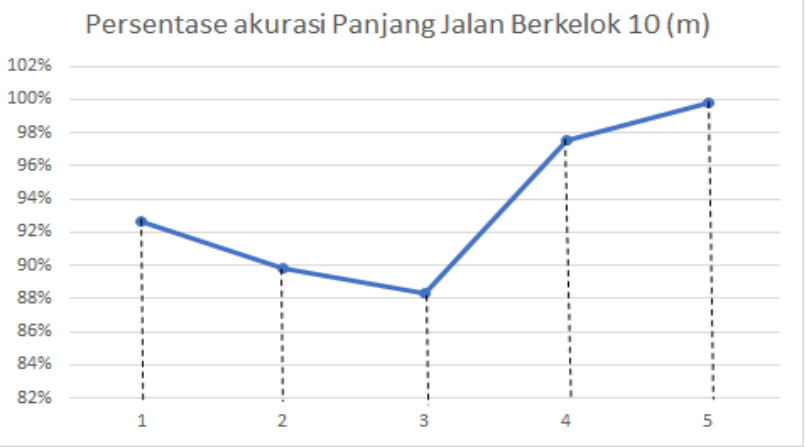

Gambar 10 Prosentase akurasi Panjang jalan berkelok 10 meter

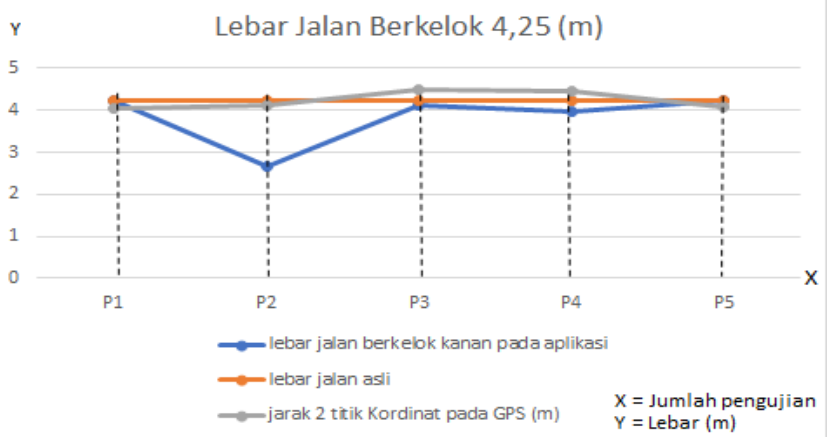

Gambar 11 Lebar jalan berkelok

Dixy Abdul Rochman S, Lisa Kristiana, Marisa Premitasari

Jurnal Ilmiah Teknologi Informasi Terapan

Volume 6, No 2, 15 April 2020 


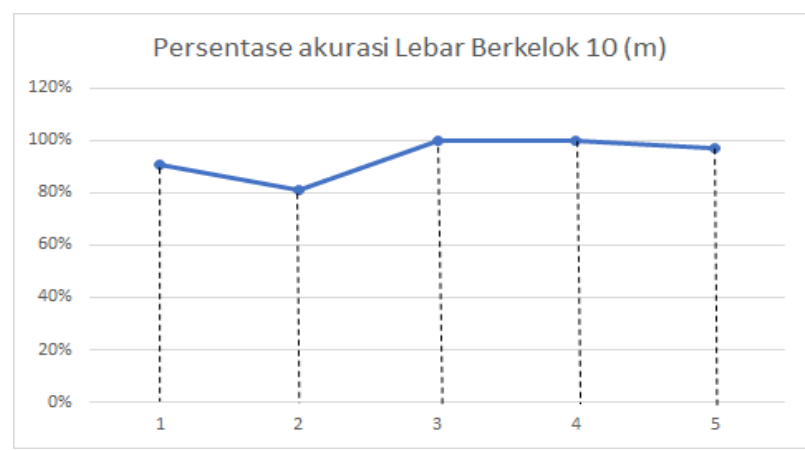

Gambar 12 Presentase akurasi lebar jalan berkelok

Pada statistik data pengukuran berkelok menunjukan pola menurun namun pada pengujian ke 5 menunjukan pola hampir mendekati dan faktor yang mempengaruhi adalah faktor kecepatan pada saat pengambilan dari titik pertama sampai titik akhir, maksud dari kecepatan di sini adalah kecepatan jalan operator aplikasi dari titik awal ke titik akhir.

Berikutnya untuk pengujian jalan berbelok $90^{\circ}$ dan kekanan untuk pengukuran panjang sisi miring atas dibagi lebar atas ditambah panjang sisi miring bawah dibagi lebar bawah seperti pada gambar 4 layout jalan berkelok, lokasi pengujian dilakukan di Jl. Cikutra Baru Raya 25-28, Neglasari, Kec. Cibeunying Kaler, Kota Bandung, Jawa Barat 40124.

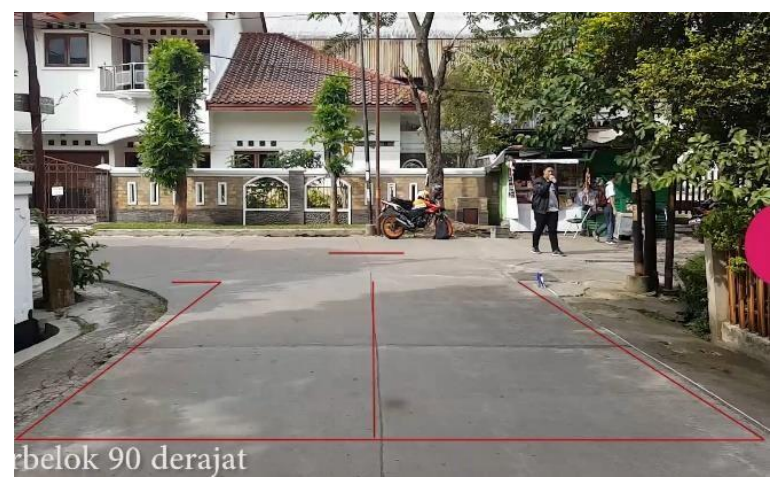

Gambar 13 Jalan berkelok kanan

Hasil dari pengujian di dapatkan grafik sebagai berikut dengan panjang jalan sebenarnya 5 meter dan lebar jalan sebenarnya 4,67 meter.

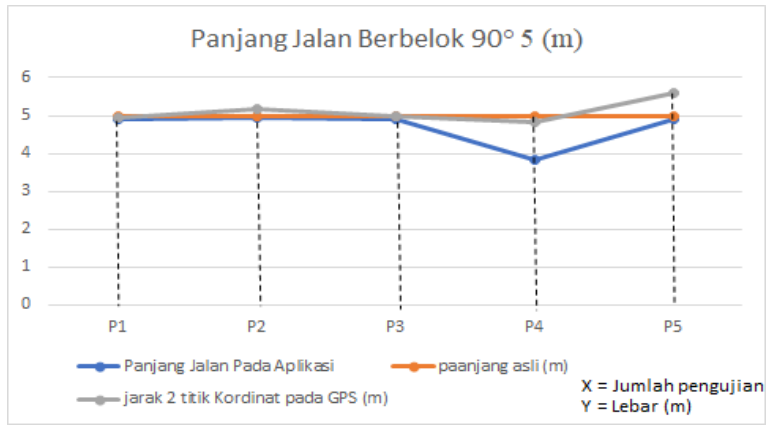

Gambar 14 Grafik Panjang jalan berkelok $90^{\circ}$

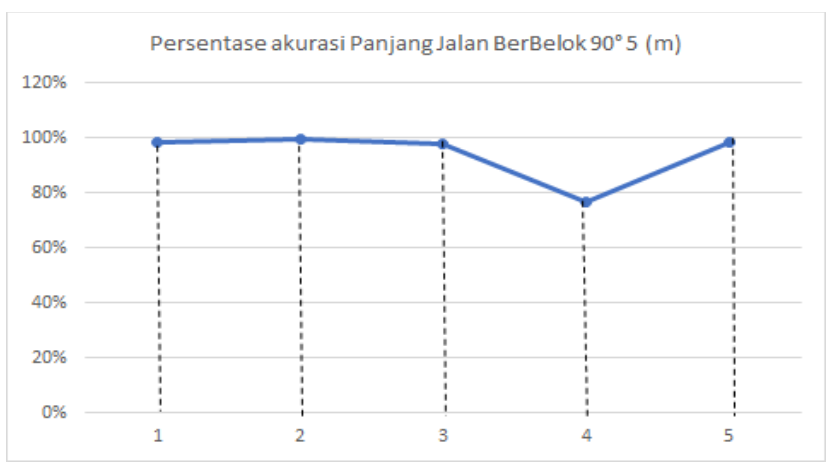

Gambar 15 Presentase akuras Panjang jalan berkelok

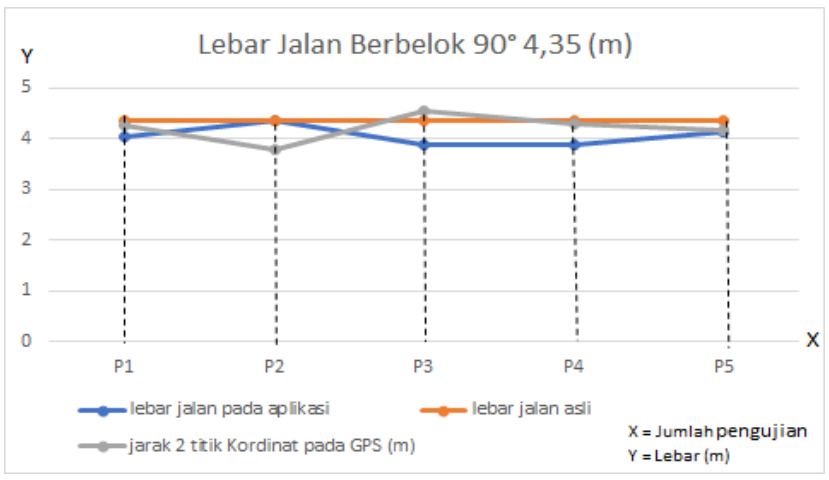

Gambar 16 Grafik lebar jalan berkelok $90^{\circ}$

Dixy Abdul Rochman S, Lisa Kristiana, Marisa Premitasari

Jurnal Ilmiah Teknologi Informasi Terapan

Volume 6, No 2, 15 April 2020 


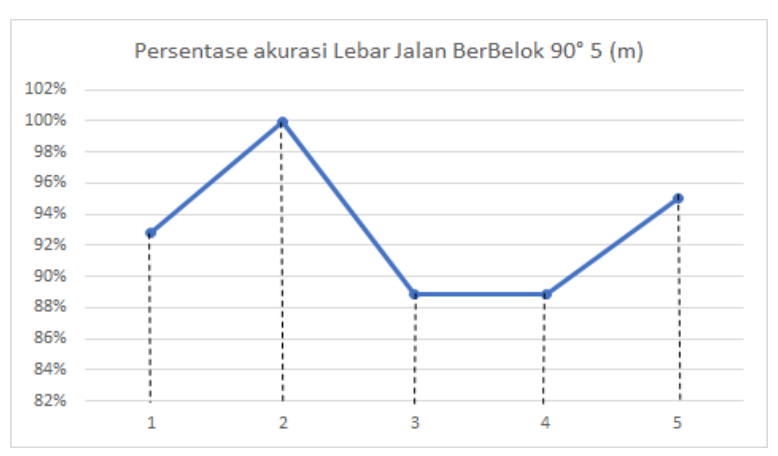

Gambar 17 Presentase akurasi lebar jalan berkelok $90^{\circ}$

\section{KESIMPULAN DAN SARAN}

Dari hasil pengujian yang telah dibahas di atas maka di dapatkan kesimpulan sebagai berikut:

Jalan yang panjang akan membutuhkan waktu yang sedikit lama beberapa detik dalam pengambilan titiknya karena ketika pengambilan titik awal ke titik akhir bila kita terlalu cepat menekan tombol pada smartphone untuk menekan tombol titik akhir GPS tidak akan presisi dengan data asli.

Perlu menunggu kurang lebih 15 detik ketika akan menekan tombol titik akhir tujuannya supaya GPS bisa membaca koordinat dengan benar tepat pada titik koordinat sehingga nilai tidak akan melebihi atau tidak sesuai dengan data asli.

Perlunya pemahaman lebih lanjut mengenai GPS pada smartphone, pada Hp outdoor, dan GPS untuk menjelajah hutan.

\section{REFERENSI}

Aprisa, dkk 2015. Rancang Bangun Sistem Informasi Monitoring Perkembangan Proyek Berbasis Web (Studi Kasus: Pt. Inti Pratama Semesta) .

Hape, F. 2016 Monitoring Pelaksanaan Pekerjaan Pada Proyek Bangunan Pergudangan Double Dengan Metode Konsep Nilai Hasil

Hidayati, N. dkk. 2016 .Analisis Kinerja TCP/IP untuk Jaringan Nirkabel Bergerak 3G di Surabaya

Karunia, M 2016. Analisis Risiko Keterlambatan Waktu Pada Proyek (Studi Kasus: Pembangunan Jalan Tol Trans Sumatera Bakauheni-Terbanggi Besar (Paket Ii Sidomulyo-Kotabaru Sta.
Prakoso, dkk,. 2017 Aplikasi Pemantauan Pembangunan Tower Base Transceiver Station Pada PT Senopati Anak Negeri Berbasis Web.

Rachmat, N . 2015. Melakukan penelitian yang berjudul Tracking Kendaraan Mobil Dengan Pemanfaatan GPS Berbasis Android.

Rinaldy Maulidiansyah, Deny Fauzy Rakhman., dkk,. 2017 Melakukan penelitian dengan judul Aplikasi Pelaporan Kerusakan Jalan Tol Menggunakan Layanan Web Service Berbasis Android

Sakinah, B. 2015. Analisis Penyebab Keterlambatan Pada Pekerjaan Konstruksi Jalan Kabupaten Lombok Tengah Dengan Metode Analisa Faktor

S. H. Khraisat, Yahya., dkk., 2015 Penelitian ini berjudul Sistem Navigasi GPS dan alat pelacak.

Sigit Sugiarto., dkk . 2015. Analisis Kesalahan Dalam Menyelesaikan Soal-Soal Dimensi Tiga Pada Siswa Kelas X Sma Negeri 2 Kendari.

Sholih Faris Asrofi. 2017 Implementasi Trigonometri Pada Pengukuran Tinggi Badan Menggunakan Arduino Mega 2560

Winardi., dkk., 2014 Penentuan Posisi Dengan GPS Untuk Survei Terumbu Karang.

Winardi., dkk., 2014 Penentuan Posisi Dengan GPS Untuk Survei Terumbu Karang.

Wirnanda., dkk., 2018 Tingkat Kerusakan Jalan Dan Pengarunya Terhadap Kecepatan Kendaraan (Studi Kasus: Jalan Blang Bintang Lama Dan Jalan Teungku Hasan Dibakoi).

Zarnelli, dkk. 2015. Sistem Informasi Monitoring Progres Pelaksanaan Proyek (P3). (Studi Kasus : Dinas Bina Marga Provinsi Riau).

Dixy Abdul Rochman S, Lisa Kristiana, Marisa Premitasari

Jurnal Ilmiah Teknologi Informasi Terapan Volume 6, No 2, 15 April 2020 